\title{
Bridge scour reliability under changing environmental conditions
}

\author{
Boulent Imam, Alexandros Kallias
}

DOI: https://doi.org/10.5592/CO/BSHM2017.5.2

Department of Civil and Environmental Engineering, University of Surrey, Guildford, Surrey, GU2 7XH, United Kingdom,

E-mail:b.imam@surrey.ac.uk.

\begin{abstract}
In this paper, a framework is presented for the probabilistic assessment of scour prone bridges considering the potential effects of changing flow characteristics due to climate change. In this methodology, statistical analysis of the expected maximum annual flow is combined with Monte Carlo simulation (MCS) to estimate the probability of scour failure. The uncertainties associated with the different factors which influence scour performance are taken into account using suitable distributions. The influence of climate change on the flow characteristics is considered through changes in the mean and variability (i.e. standard deviation) of the expected maximum annual flow distribution. The methodology is demonstrated through a case study using a bridge in the UK. The results from this investigation revealed that a time-dependent increase in the mean of the expected maximum annual flow can have an adverse effect on local scour performance which is greater in magnitude compared to an increase of its variability (i.e. standard deviation) alone. Amongst the cases examined, however, the most adverse effect on scour performance is observed from the simultaneous increase in both mean and variability of the expected maximum annual flow. The results also highlighted the significance of the uncertainty in foundation depth, commonly present in old bridges, and local scour modelling when estimating scour reliability.
\end{abstract}

Keywords: bridges, local scour, probabilistic analysis, Monte Carlo simulation, climate change

\section{Introduction and Background}

Scour is identified as one of most widespread causes of structural failure in bridges spanning over rivers (Wardhana \& Hadipriono, 2003). Scour is characterised by the erosion/removal of (underwater) river bed material in the vicinity of the piers which can lead to structural instability if the foundation depth is reached. A number of factors are associated with the scour depths which may potentially develop at the pier and/or abutments of a bridge including, among others, the geometrical characteristics of the pier/abutment, the river characteristics including bed material and angle of attack as well as the flow magnitude at the bridge location. The scour phenomenon has been extensively investigated and a number of - mainly empirical - models are available which allow the quantification of scour depths considering the most significant influencing factors such as pier geometry, river and flow characteristics (Melville \& Coleman, 2000). The prediction of scour depths in practice involves significant uncertainty caused by the variability associated with the above parameters as well as the scour prediction models themselves, which have been developed empirically through small-scale laboratory experiments.

A source of uncertainty which is becoming increasingly relevant when predicting future scour performance of bridges is the potential influence of climate change. The increased risk of scour of bridges due to climate change has been recognised worldwide (Transportation Research Board, 2008; DEFRA, 2012). The potential consequences of climate change on bridge scour performance are currently under-researched, on a quantitative basis, and need to be investigated to assist the development and implementation of adaptation strategies (Meyer \& Weigel, 2011). Hence, capturing the aforementioned uncertainties in the analysis would allow a more reliable performance assessment of scour prone bridges and assist towards more efficient decision-making under conditions of uncertainty.

An important parameter which directly affects the depth of the developing scour hole is the magnitude of the flow which may potentially be encountered in a river at the bridge location. The flow magnitude in a river is governed by several factors such as catchment characteristics, precipitation patterns, etc. Climate change is predicted to cause changes in the river flow characteristics due to changes in the precipitation patterns and catchment characteristics (Robson, 2002). A number of methods have been devised to predict the potential flow in a particular river, for instance through statistical analysis of historic flow records or alternatively using the 
rainfall-runoff method which requires knowledge of the precipitation patterns and the catchment descriptors. The statistical analysis of historic flow records through the widely-used WINFAP-FEH 3 software (Robson \& Reed, 1999) allows the estimation of the statistical properties of the expected maximum annual flow for any river in the UK.

Alterations in the climatic and weather conditions due to climate change can potentially increase the uncertainty associated with the magnitude as well as the prediction of extreme weather events including extreme precipitation and river flows. The available evidence suggests that these changes may prevail as temporal changes in the statistical properties and distribution of key climatic parameters such as temperature and precipitation (Katz, 1993). Increasing flood frequency and magnitude due to increasing precipitation and/or changes to the catchment characteristics can have a significant effect on the scour performance of bridges. At present, it is difficult to precisely quantify the effect of climate change in terms of precipitation and temperature changes on fluvial flood frequency and magnitude. However, the results of several studies suggest that in some areas flood frequency and magnitude will increase in the future (i.e. occurrence of extreme events will become more frequent).

This paper aims to provide a framework for the scour reliability assessment under changing uncertain flow characteristics due to climate change. In view of the above limitations, an alternative probabilistic approach is suggested in this paper to quantify the effect of potential increase of flood frequency and magnitude due to climate change on the probability of local scour failure. Firstly, the distribution of the expected maximum annual flow is obtained using statistical analysis of existing flow records. Thereafter, gradual changes are introduced to the statistical properties of the flow to account for climate change and Monte Carlo simulation (MCS) is used to estimate the probability of scour failure over time. A case study of a UK bridge is carried out to investigate the potential effects of changing mean and variability of the expected maximum annual flow on the probability of local scour failure in bridge piers to demonstrate the applicability of the proposed framework.

\section{Probabilistic Framework}

In this paper, local scour is estimated using the HEC-18 design equation (Arneson et al., 2012), given by Eq. (1), which considers scour as a time-independent process, i.e. temporal effects of local scour development are not modelled

$$
y_{\max }=2 y_{0} K_{1} K_{2} K_{3} K_{4}\left(\frac{D}{y_{0}}\right)^{0.65} F_{0}^{0.43}
$$

where $y_{\max }$ is the maximum scour depth (m), $y_{0}$ is the depth (m) of the flow upstream of the bridge pier, $K_{1}, K_{2}$, $K_{3}$ and $K_{4}$ are coefficients which allow for pier shape, angle of attack, streambed conditions and the river bed material size, $D$ is the pier diameter and $F_{0}$ is the Froude number given by

$$
F_{0}=\frac{V}{\left(g y_{0}\right)^{0.5}}
$$

where $V$ is flow velocity given by

$$
V=\frac{Q}{B y_{0}}
$$

and the flow depth $y_{0}$ is given by $(\mathrm{BD}, 2012)$

$$
y_{0}=\left(\frac{n Q}{B s^{1 / 2}}\right)^{3 / 5}
$$

where $Q$ is the flow $\left(\mathrm{m}^{3} / \mathrm{s}\right), B$ is the river width $(\mathrm{m}), n$ is the Manning's coefficient and $s$ is the longitudinal slope of the channel. Eq. (4) can be used for wide rivers with ratios $B / y_{0}$ exceeding about 10 , giving conservative predictions for cases where this is less than about 10 (BD, 2012). In this paper, the flow $Q$ is estimated using the statistical analysis procedures implemented in the software WINFAP-FEH 3 (Robson \& Reed, 1999).

In terms of the probabilistic framework for the scour analyses, the performance function for the limit state for local scour of a bridge pier is given by 

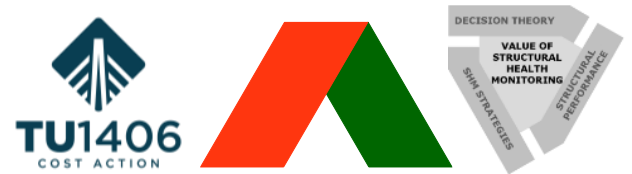

$$
G(t)=D_{F}-y_{\max }(t)=D_{F}-\left[2 y_{0}(t) K_{1} K_{2} K_{3} K_{4}\left(\frac{D}{y_{0}(t)}\right)^{0.65} F_{0}(t)^{0.43}\right]
$$

where $D_{F}$ is the foundation depth. $G(t) \leq 0$ indicates the failure realization of the limit state. Using the statistical properties, including distribution type, for the random variables of Eq. (5) and assuming that the resistance $D_{F}$ and the load effects $y_{\max }(t)$ are statistically independent, the instantaneous (annual) probability of failure, $p_{f}(t)$, is given by

$$
p_{f}(t)=P[G(t) \leq 0]
$$

Eq. (6) is evaluated using Monte Carlo simulation using a sample size of $n=2 \times 10^{6}$ per year. Table 1 shows the random variables and their characteristics. Flow events in different years are assumed to be independent. The cumulative (time-dependent) probability of failure, at any point within a time period, is given by Eq. (7) below, provided that the failures are statistically independent.

$$
p_{f}\left(0, t_{L}\right)=1-\prod_{i=1}^{k}\left\{1-P\left[G_{t_{i}}(t) \leq 0\right]\right\}
$$

The expected maximum annual flow is modelled by fitting a suitable distribution to flood data using the statistical procedures implemented in WINFAP-FEH 3 (Robson \& Reed, 1999). This approach is based on the creation and analysis of a pooling group of several catchments of similar hydrological characteristics, with the available years of flow records for each station (in the different catchments) contributing to the total number of

\begin{tabular}{|c|c|c|c|c|c|}
\hline & Variable & Mean & $\mathrm{CoV}$ & Distr. & Ref. \\
\hline \multirow{5}{*}{$\stackrel{\overline{0}}{a}$} & $B(\mathrm{~m})$ & 65 & 0.05 & Normal & Assumed \\
\hline & $K_{3}$ & 1.1 & 0.05 & Uniform & NCHRP (2003) \\
\hline & $K_{4}$ & 1.0 & - & - & - \\
\hline & $s$ & 0.0032 & 0.05 & Lognormal & Assumed \\
\hline & $n$ & 0.035 & 0.28 & Lognormal & NCHRP (2003) \\
\hline \multirow{4}{*}{ 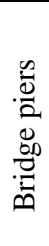 } & $D_{F}(\mathrm{~m})$ & 4.5 & - & - & Assumed \\
\hline & $K_{1}$ & 1.0 & - & - & Assumed \\
\hline & $K_{2}$ & 1.0 & - & - & Assumed \\
\hline & $D(\mathrm{~m})$ & 2 & 0.05 & Normal & Assumed \\
\hline
\end{tabular}
station years.

Table 1. Statistical properties of random variables.

\section{Bridge Case Study}

The bridge considered in this case study is assumed to be located on river Earn in Scotland, UK, assuming alluvial riverbed conditions. WINFAP-FEH 3 provides a number of options for estimating QMED, which is the maximum annual flow with a return period $\mathrm{T}=2$ years), for instance using the catchment descriptors or annual maxima (AM) series (for more details see Robson and Reed 1999). In this paper, a QMED of $250.2 \mathrm{~m}^{3} / \mathrm{s}$ is estimated from annual maxima series of the station. Analysis of pooling group flood data (i.e. annual maximum series) using the WINFAP-FEH 3 software indicates that the generalized extreme value (GEV) distribution, given by Eq. (8) (Kottegoda \& Rosso, 1997), is the most suitable distribution for modelling the magnitude of the expected maximum annual flow; its cumulative distribution function is expressed as follows

$$
F_{X \max }=\exp \left\{-\left[1-\frac{k(x-\varepsilon)}{\alpha}\right]^{1 / k}\right\}
$$


where $k$ is the shape parameter, $\varepsilon$ is the location parameter and $\alpha$ is the scale parameter. The GEV distribution parameters obtained from the statistical analysis of stations in similar catchments (i.e. pooling group) in WINFAP are $\alpha=0.222, \varepsilon=0.919$ and $k=0.002$. The scale and location parameters of the GEV distribution are given by Eqs. (9) and (10), respectively (Kottegoda \& Rosso, 1997)

$$
\begin{gathered}
\alpha=\sqrt{\frac{k^{2} \sigma^{2}}{\Gamma(1+2 k)-\Gamma^{2}(1+k)}} \\
\varepsilon=\mu-\frac{\alpha}{k}[1-\Gamma(1+k)]
\end{gathered}
$$

where $\mu$ is the sample mean, $\sigma$ is the sample standard deviation and $k, \varepsilon$ and $\alpha$ are the shape, location and scale parameters of the generalized extreme value distribution, respectively (Kottegoda \& Rosso, 1997). $\Gamma$ is the gamma function.

The potential effects of climate change on scour are examined through a parametric study in which the scale and location parameters are gradually changed for increasing values in the mean $\mu$ and variability (i.e. standard deviation $\sigma$ ) of the flood magnitude in Eqs. (9) and (10). The different analysis cases examined in relation to changing flow conditions are follows: $20 \%, 40 \%$ and $60 \%$ increase in the mean value; $20 \%, 40 \%$ and $60 \%$ increase in the standard deviation (variability) and 20\%, $40 \%$ and $60 \%$ simultaneous increase in both. These changes are assumed to evolve linearly with time over a 60 year period. In this way, the effects of climate change on the precipitation patterns and catchment descriptors and hence on the flood frequency and magnitude are implicitly considered in the analysis of the different scenarios examined. A foundation depth (FD) of $4.5 \mathrm{~m}$ is assumed to facilitate the estimation of the scour failure probability.

\section{Results and Discussion}

Fig. 1 (left) shows the effect of increasing the mean in the expected maximum annual flow on the annual and time-dependent probabilities of failure for the scenarios with mean increases of 20\% (45M2000), 40\% $(45 \mathrm{M} 4000)$ and $60 \%$ (45M6000) over a 60 year period. The results in this figure indicate that the effect of increasing mean is relatively small for the initial 10 years and it gradually becomes noticeable between 10 and 20 years and significant beyond the initial 20 year period. At the end of the examined period the time-dependent probabilities of failure for the scenarios with $20 \%, 40 \%$ and $60 \%$ increase in mean are predicted to be approximately $60 \%, 175 \%$ and $340 \%$, respectively, higher than the base line scenario (45M0000) which assumes no changes in the statistical properties of the expected maximum annual flow over time.

Fig. 1 (right) shows the effect of increasing variability (standard deviation) in the expected maximum annual flow on the annual and time-dependent probabilities of failure for the scenarios with variability increases of $20 \%$ (45M0020), 40\% (45M0040) and 60\% (45M0060) over a 60 year period. The results in this figure indicate that the effect of increasing variability is relatively small for the initial 15 years and it gradually becomes significant beyond the initial 20 year period. For the analysis cases examined, the effect of increasing variability in the expected maximum annual flow is predicted to have a relatively smaller effect on the failure probabilities compared to the previous case of assuming a gradually increasing mean. The time-dependent failure probabilities at the end of the 60 year period are predicted to increase by approximately $40 \%, 90 \%$ and $150 \%$ for cases 45M0020, 45M4040 and 45M0060, respectively relative to the base line case (45M0000).
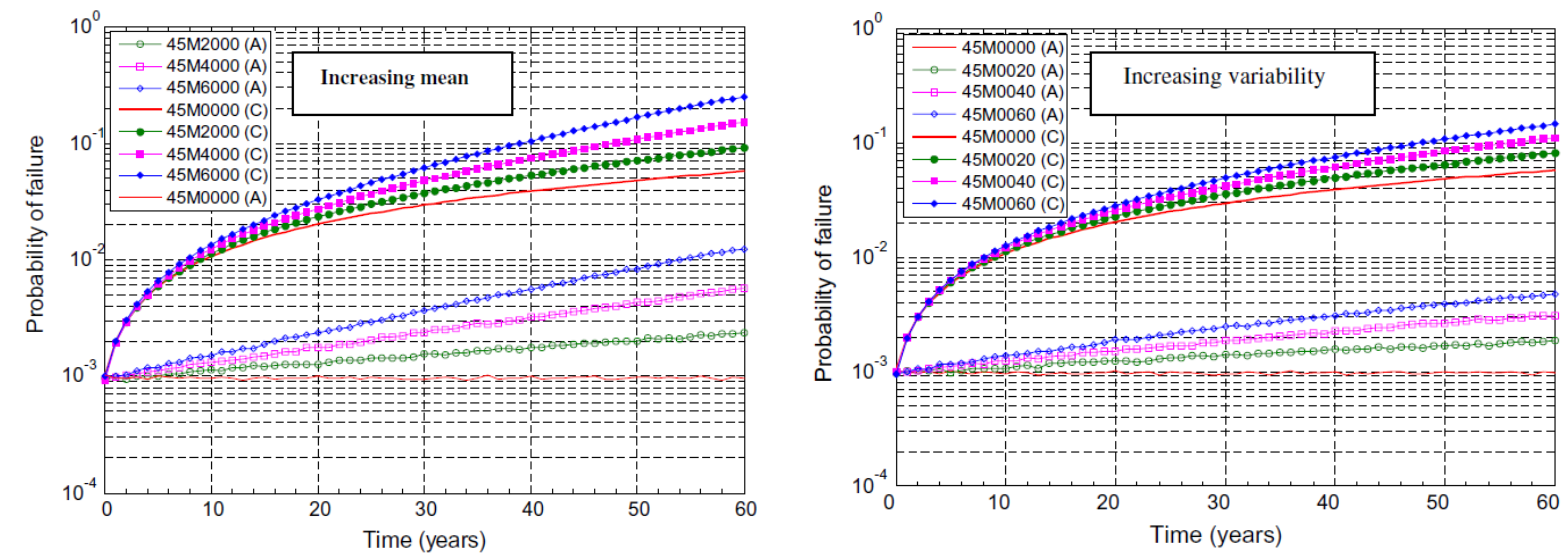

Fig. 1. Effect of increasing mean (left) and variability (standard deviation) (right) in the expected maximum annual flow on the annual (A) and cumulative time-dependent (C) probabilities of scour failure. 

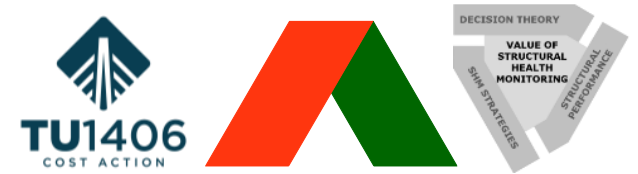

The Value of Structural Health Monitoring for the reliable Bridge Management

Fig. 2(left) shows the cumulative probabilities of scour failure for the previous analysis cases for different foundation depths, i.e. $3.5 \mathrm{~m}, 4 \mathrm{~m}$ and $5 \mathrm{~m}$. As expected, the results in this figure clearly show the influence of foundation depth $\left(D_{F}\right)$ on the predicted time-dependent $p_{f}$; with smaller foundation depths having higher probabilities of failure. For the case of FD $=3.5 \mathrm{~m}$ the effect of changes in the statistical properties of the flow (i.e. increasing mean or/and variability) have an insignificant effect on the time-dependent probabilities of scour failure. The results further indicate that the effect of increasing mean and/or variability is not constant when different foundations depths are considered. For example, for the case of FD $=5 \mathrm{~m}$, the increasing variability of the expected maximum annual flow has a greater effect than the increasing mean. Conversely, the increasing mean of the expected maximum annual flow distribution has a greater effect compared to the effect of increasing variability for decreasing foundation depths. As shown in Fig. 2(left), the simultaneous increase of mean and variability of the flow distribution produces the highest probabilities of failure in all cases examined. These results indicate that foundation depth has a significant effect on the predictions. In practice, this variable is deemed with high uncertainty while in many cases no data is available on the actual foundation type and depth of a particular bridge (JBA, 2004). In such cases, conservative values of FD are recommended in assessing scour performance (JBA, 2004). To this end, the systematic collection of actual foundation depth measurements of piers in scour prone bridges would reduce the uncertainty and hence improve the accuracy of the scour failure predictions during assessments.
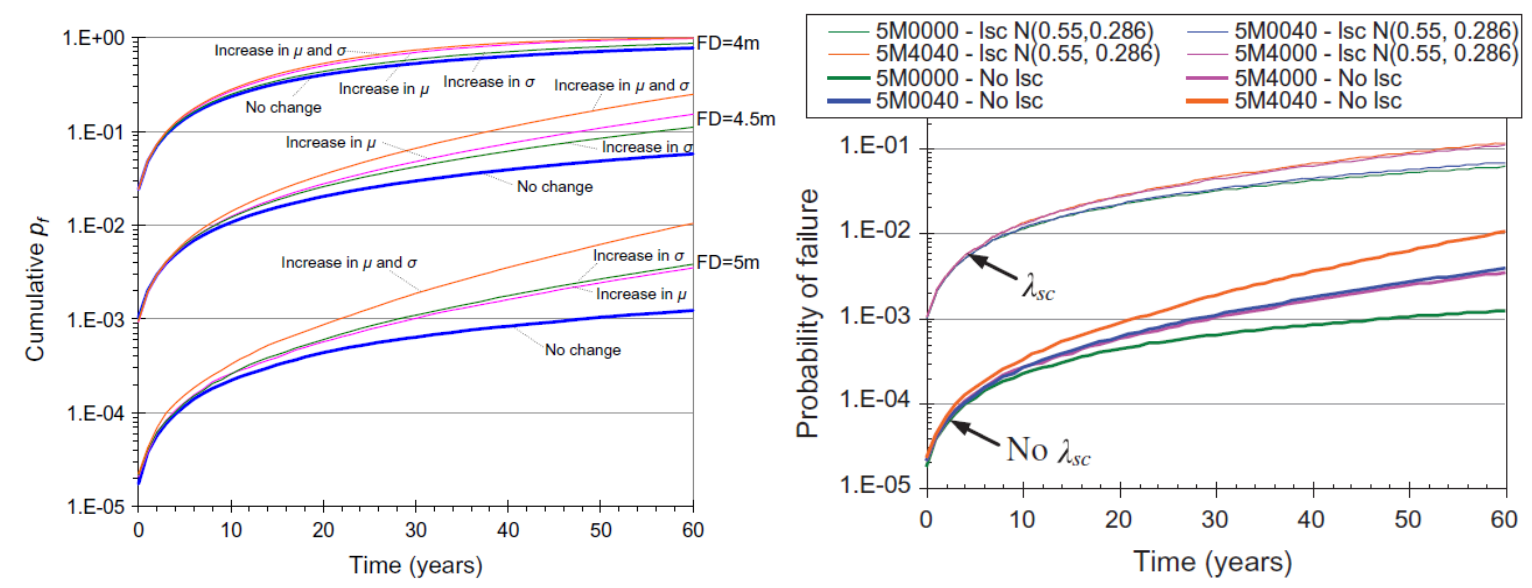

Fig. 2. (left) Effect of foundation depth on time-dependent probability of scour failure; (right) effect of model parameter $\lambda_{\text {sc }}$ on the time-dependent probabilities of local scour failure for up to $40 \%$ increase in the mean or/and variability of the expected maximum annual flow distribution for a foundation depth $=5 \mathrm{~m}$.

It has been shown that the scour equation (Eq. (1)) of HEC-18 leads to conservative predictions of local scour (NCHRP, 2003). This is due to the fact that the scour prediction models used in codes of practice have been developed through small-scale laboratory experiments. Comparisons of these prediction models with field measurements of scour depths on real bridges have shown that there is a discrepancy between them. It has been suggested that a model parameter $\lambda_{s c}$ can be introduced in Eq. (1) to reduce its conservatism (NCHRP, 2003) inherently taking into account epistemic uncertainty. The local scour model is now given by Eq. (11):

$$
y_{\max }(t)=2 \lambda_{s c} y_{0}(t) K_{1} K_{2} K_{3} K_{4}\left(\frac{D}{y_{0}(t)}\right)^{0.65} F_{0}(t)^{0.43}
$$

Several values have been proposed for the statistical properties of $\lambda_{s c}$; for a summary see (NCHRP, 2003). To investigate the influence of this parameter a number of scenarios are considered using values for the statistical properties of $\lambda_{s c}$ suggested in (NCHRP, 2003). The analysis cases in this section assume a $40 \%$ gradual increase in mean, standard deviation and the simultaneous increase of both for the expected maximum annual flow considering a foundation depths of $5 \mathrm{~m}$. The model parameter $\lambda_{s c}$ is modelled using a normal distribution with mean $=0.55$ and $\mathrm{COV}=52 \%(\mathrm{NCHRP}, 2003)$. In this way comparisons can be made with results presented in previous sections.

Fig. 2(right) shows the predicted time-dependent failure probabilities for the analysis case with foundation depth of $5 \mathrm{~m}$. The results in these figures indicate that although the mean value of $\lambda_{s c}$ is less than 1 (i.e. mean value of 
$\left.\lambda_{s c}=0.55\right)$, the introduction of this model parameter causes an increase of the predicted time-dependent failure probabilities due to the high variability associated with model parameter $\lambda_{s c}$ resulting in an increase of the scour depth values exceeding $5 \mathrm{~m}$ (generated using MCS in MATLAB). As expected, the mean value of the predicted scour depths is lower than the predicted scour depths when $\lambda_{s c}=1$. The results in Fig. 2(right) also indicate that the very high variability of the model parameter $\lambda_{s c}(\mathrm{COV}=0.52)$ overshadows the effect of the assumed increasing variability in the expected maximum annual flow on the predicted time-dependent probabilities of failure (i.e. the increasing variability of flow is predicted to have an insignificant effect on cumulative $p_{f}$ ).

\section{Conclusions}

In this paper a probabilistic methodology was presented for the reliability analysis of local scour in bridge piers, considering the potential effects of climate change through changes in the distribution of the expected maximum annual flow. The procedure was demonstrated though a case study using a bridge located in the UK in which a number of analysis cases were considered to investigate the potential effect of changing flow characteristics on the probability of scour failure. It was found that the effects of gradually increasing mean or variability of the expected maximum annual flow on the predicted probabilities of scour failure were found to be relatively small for the initial 10-15 years. Beyond this initial period their effect on the predicted probabilities of failure becomes significant, with the case of simultaneous increase in mean and variability of the flow having the greatest impact on the predictions. The foundation depth and scour modelling uncertainty was found to have a significant effect on scour failure probability. The results of the case study presented in this paper indicate that the effects of changing flow characteristics on the scour failure probabilities are predicted to reduce with reducing foundation depths. More specifically, when considering the effect of foundation depth in conjunction with changing flow characteristics on the scour failure probability, the results showed that the effects of increasing mean and/or variability of the maximum expected annual flow was more significant in the cases with deeper foundation depths are assumed in the analysis.

\section{References}

Arneson L.A., Zevenbergen L.W., Lagasse P.F., Clopper P.E. Evaluating scour at bridges, $5^{\text {th }}$ Edition, Hydraulic Engineering Circular No. 18 (HEC-18), FHWA-HIF-12-003, U.S. Department of Transportation, Federal Highway Administration, 2012.

BD 97/12. The assessment of scour and other hydraulic actions at highway structures, Design Manual for Roads and Bridges, Highway Structures: Inspection and Maintenance Assessment, Vol. 3, Sec.4, Part 21, UK, 2012.

Department for Environment, Food and Rural Affairs (DEFRA). The UK Climate Change Risk Assessment 2012; Evidence Report, Project Deliverable D.4.2.1. London, 2012.

Katz RW. Towards a statistical paradigm for climate change. Climate Research, 2: 167-75, 1993.

Kottegoda N.T., Rosso R. Statistics, probability and reliability for civil and environmental engineers. McGrawHill, 451-2, 1997.

Melville B.W., Coleman S.E. Bridge scour. Water Resources Publications, 2000.

Meyer M.D., Weigel B. Climate change and transport engineering: preparing for a sustainable future. Journal of Transportation Engineering, 137(6): 393-403, 2011.

NCHRP. Design of highway bridges for extreme events. Report 489, National Cooperative Highway Research Program, Transportation Research Board, New York, 2003.

Robson A., Reed D. Statistical procedures for flood frequency estimation Flood Estimation Handbook, Volume 3, Centre for Ecology \& Hydrology, Natural Environment Research Council, Wallingford, Oxfordshire. 1999.

Robson A.J. Evidence for trends in UK flooding. Philosophical Transactions of the Royal Society London A, 360: 1327-1343, 2002.

Transportation Research Board. Potential impacts of climate change on U.S. Transportation. Transportation Research Board Special Report 290, Committee on Climate Change and U.S. Transportation, National Research Council, Washington D.C, 2008.

Wardhana K., Hadipriono F.C. Analysis of recent bridge failures in the United States. Journal of Performance of Constructed Facilities, 17(3): 144-150, 2003. 